\title{
Physical Education Reform of University in Lifelong Physical Education
}

\author{
Zhilan Ma \\ Department of Physical Education, Bohai University, Jinzhou, 121013, China \\ 478656121@qq.com
}

Keywords: lifelong education, lifelong physical education, university, physical education reform

\begin{abstract}
The university physical education reform under the perspective of lifelong physical education, can make the students in the campus life and future work adhere to exercise and to ensure that the lifelong physical education throughout the student's work and life, realize the integration and sustainable development of physical education. This paper analyzes the relation between the lifelong physical education and university sports, studied the content of the lifelong physical education in university and universities, points out the problems existing in the sports education in university and universities, puts forward university physical education reform under the perspective of lifelong physical education content. Specific reform content including: strengthen the flexibility of the sports teaching content and universality, help students build up their thought of lifelong physical education and teaching in cultivating the students' sports ability, the establishment of a social participation sports management mechanism, carry out rich and colorful extracurricular sports activities.
\end{abstract}

\section{Introduction}

Lifelong education refers to the stages in the life of people the sum total of all kinds of education, comprehensive, is the unification of different types of education advocated in moments of need with necessary knowledge and skills in the best possible way. The lifelong education thought has been the guiding principle of education reform in many countries. Lifelong education makes education a whole new interpretation, arguing that education runs through the life of people, and completely changes the concept of dividing people's life into two stages, study period and working period; lifelong education has promoted the establishment of education socialization and learning society. Change the old idea that the school is the only education institution, so that education goes beyond the limitations of education of the school, thus extending to the whole space of human social life; Lifelong education has revolutionized the education content and teacher-student relationship. Education is not simple knowledge transfer, but should implement the person's overall development spirit, the learners should not only learn the existing culture, but also cultivate the individual's active adaptability to the environmental change. The traditional teacher-student relationship will also change fundamentally, with a new, democratic and open relationship; Lifelong education points out a new way of self-development and self-improvement for learners.

Lifelong physical education, refers to a person's lifetime of physical exercise and the acceptance of sports education combined. During the life of the people, we will continue to do physical exercise, so as to achieve the goal of physical and mental health; In under the guidance of lifelong physical education thought to sports of systematic, holistic and science into a target, for life in different periods and different areas of life, take part in physical exercise and the ideological education opportunities of practice. The main ideas of lifelong physical education, is to make people's life constantly accept physical education and lifelong physical training, make the pre-school sports, school sports, family sports and community sports, such as multiple link of sports education are closely linked, so as to ensure the unity, integrity and continuity of physical education, make its implementation integration. School sports is the foundation of lifelong physical education, sports interests and habits are the precondition for students to study independently and to keep exercising for life. Whether the teaching content choice or the updating of the teaching method 
should focus on the students' interest in sports, only stimulate the students' interest in sports, so that the students can exercise actively and consciously.

Sports is an important part of education's career, and it is also an important part of lifelong education for life. The lifelong physical education of the lifelong education is about everyone's physical health. Although lifelong physical education are closely linked to family education and social education, the role played by the school in the development of lifelong physical education is also extremely important. In physical education teaching in universities to carry out lifelong education idea, let the students to accept a comprehensive system of physical education teaching, and in the future life of the students and keep the habit of physical exercise, improve the overall quality of life in the lifelong physical education. The university physical education reform under the perspective of lifelong physical education, can make the students in the campus life and future work adhere to exercise and to ensure that the lifelong physical education throughout the student's work and life, realize the integration and sustainable development of sports teaching.

\section{Relationship between Lifelong Physical Education and Lifelong Education}

The lifelong education has direct enlightenment to the formation and development of lifelong physical education thinking, and lifelong education has given birth to the formation of the concept of lifelong physical education. Education has long had the motto "live and learn". In the same way, for the healthy and future life of people, there should also be the concept of "live and exercise till old". The promotion of human health and the quality of the whole people cannot be achieved without lifelong physical education, and sports will permeate the whole education process in the form of a necessary element. Lifelong physical education is the foundation of the lifelong education in the school sports education theory, to strengthen the teaching of the basic sports knowledge, improve the understanding of sports, the popularization and promotion of sports knowledge, change the sports teaching content is monotonous, divorced from reality, lack of the flavor of era.

Lifelong physical education meet the needs of The Times and the internal needs of health. Lifelong physical education is no longer a matter of "want" for people, but a rise to a new level of understanding of lifelong physical education. The lifelong physical education is also continuously self-improvement and scientific development, which is regarded as a cross-century sports thought. The formation of lifelong physical education thinking is the expansion and supplement of lifelong education. The idea of lifelong physical education has further enriched and perfected the lifelong education thought system, and there are many links between them.

\section{Relationship between Lifelong Physical Education and University Physical Education}

School sports is the foundation of lifelong physical education. As the last link of school sports, university sports is the key link in the transition from school sports to social sports. University sports plays an important role in the system of lifelong physical education and has a profound influence on cultivating students' lifelong physical education consciousness. There are differences and commonalities between university sports and lifelong physical education.

The difference between the university sports and lifelong physical education basically has the following two points: first, from the form, physical education is an important part of school physical education in universities, is a course that is a purposeful, planned and organized activities. In the course of teaching, equipped with physical education teachers, provide the venue and equipment, and conduct the assessment. While lifelong physical education are not limited to space, time and form, content is also colorful, people can choose their own sports activities according to their preferences and needs; Secondly, from the perspective of objects, university sports are oriented towards college students, and lifelong physical education are for all members of society. Although university sports are only for a small number of specific groups, they have cultivated a group that is particularly important for lifelong physical education.

There are three main points in university sports and lifelong physical education: first, the ultimate goal of university sports and lifelong physical education is to "educate people". The 
university stage is the golden stage of all-round development of physical quality and physical fitness, and good physical quality promotes intellectual development and spiritual civilization construction. Lifelong physical education combine physical exercise with learning, work and life; Secondly, university sports and lifelong physical education are mainly aimed at enhancing physical fitness as the main means of physical exercise. Although physical fitness depends on many factors, the most active and important factor is physical exercise. In university physical education, physical education is indispensable to both physical education and sports training. Lifelong physical education can make young people healthy, middle-aged people energetic and old people live longer; Third, the university sports and the lifelong physical education all contain education and teaching content, all need to learn to master the sports knowledge and sports technology, further improve the athletic ability. Therefore, in the teaching and competition training of university sports, it is important to pay attention to the lifelong physical education integration and cultivate students' lifelong physical education awareness and physical exercise habit.

\section{Contents of Lifelong Physical Education in University}

Lifelong physical education as an important part of lifelong education, keeping fit and educational organization, constantly enhance the whole nation's physical quality, promote the harmony of personal physical and mental health and social progress. The main content of lifelong physical education consists of four aspects:

(1) Cultivate students' awareness of sports. Sports consciousness is the product of sports practice, which is the sum of people's spiritual activities in the content, form, method, means and various internal and external relations of sports. In the course of university physical education, only attention should be paid to the cultivation of students' sports awareness to meet the needs of social development. To train students to participate in physical training is to cultivate students' lifelong physical education ability. The enhancement of sports awareness will have a powerful driving force and far-reaching impact on lifelong physical education.

(2) Cultivate students' interest in sports. Sports interest is based on the students' exploration of sports activities, and actively engaged in the psychological tendency of sports activities, affecting the direction and intensity of sports participation. Sports interest is the foundation of lifelong training, which is an important content of physical education in universities, which determines the students' self-motivation and independence of long-term participation in physical exercise. In the course of physical education, the active understanding of the students' interest in sports activities and the existing level, the sports activities and sports interest link.

(3) Develop the students' physical habits. Sports habit refers to the behavior pattern that occurs when repetition occurs, and its physiological mechanism is a certain situational stimulation and related action, which forms a temporary neural connection that is consolidated in the cerebral cortex. Education should fully implement the party's education policy and strive to do well in sports. To carry out lifelong physical education for students, cultivate students' awareness, skills and habits of physical exercise. Developing good sports habits is a guarantee of physical activity.

(4) Cultivate students' physical ability. Sports ability is the ability to engage in physical activity, according to the condition changes, select and apply appropriate methods of physical exercises, independent of physical exercise, reasonable arrangement of exercise time, adjust the exercise load, exercise self medical supervision, correctly evaluate the efficacy of the physical condition and exercise. The specific contents of sports ability include cognition ability of sports, scientific training ability, physical exercise self-evaluation ability, lifelong physical education ability, etc. Sports ability is the guarantee to achieve the desired effect.

\section{Existing problems of Physical Education in University}

School physical education is often neglected. In fact, physical education is as important as cultural teaching. High-quality sports education is very beneficial to students' physical and mental health development. Although the university sports teaching improve the rules and regulations, the 
introduction of the facilities and equipment, regularly organize activities of university students' sports competition, but there are still many problems, embodied in the following three aspects:

(1) The concept of physical education lags behind. The concept is the soul of action, the teaching concept plays a guiding role to the teaching, all advanced teaching reform is developed from the advanced teaching idea. Physical education teaching in universities on "teaching" rather than "learning", heavy light "results" and "process", this kind of idea in the teaching process to the teacher as the center, students have no consciousness of independent thinking, learning in a passive state, does not take the initiative thinking, excessive pursuit of the assessment results, lost interest in physical exercise.

(2) Students are not interested in physical education. The lack of sports skills is a serious problem in the training of lifelong education. Affected by traditional education, attaches great importance to the cultural course learning, despise exercise, most parents don't want to waste time and energy in the sports arena, students should have a physical exercise time deprived. Sports funds have not been invested in, the construction of PE teachers has not been strengthened, the physical education environment and conditions have not been improved obviously, and the atmosphere of physical training can not be created for students.

(3) Physical education is difficult to meet students' needs. There is a big gap between education content and real demand. In terms of physical education teaching theory, not on the development needs of the students the corresponding curriculum reform, there is no according to the student sports make out different teaching material choice, has violated the lifelong physical education goal. In practice teaching in universities, competitive sports occupy most of the time, and the imbalance of sports events is serious, affecting the improvement of students' comprehensive skills.

\section{Contents on Physical Education Reform of University in Lifelong Physical Education}

In view of the contents of lifelong physical education in university and university physical education existence question, reference to related literature, sports teaching experience for many years, to the partners is put forward under the perspectives of lifelong physical education, university physical education reform content is as follows:

(1) To enhance the elasticity and universality of physical education content. To change the traditional teaching mode of physical education, we will integrate the happiness teaching method, the experiment teaching method and the situation teaching method into the university physical education teaching. Open a variety of sports courses, help students to find the best sports skills to learn, and cultivate students' good sports behavior. Scientific design of the physical education teaching contents, using modern teaching mode, advanced teaching methods from other disciplines, combined with the students' individual differences, found that students who are interested in sports, more scientific research and digging, to promote lifelong physical education exercise habit.

(2) Help students develop lifelong physical education. Lifelong physical education are influenced by the thought of lifelong education and the development of sports. In order to promote the development of students' sports, teachers should constantly make changes in relevant sports concepts to help students develop lifelong physical education ideas. Sports teachers should also promote the students autonomous learning ability, in the process of sports teaching, fully stimulate students' innovation ability, let the students think learning sports is an interesting process, is not a traditional kind of boring exercise, further stimulate the enthusiasm of students in physical education learning and understanding of the concept of lifelong physical education.

(3) The teaching focuses on cultivating students' physical ability. Physical education teachers in the process of specific sports teaching, pay attention to students' sports imagination ability and understanding ability, through the situational teaching method and interesting teaching methods, inspire students' thinking and make students' thinking active, always improve the mastery of sports knowledge and skills, guides the student to apply sports knowledge to better exercise practice, learn to reasonably control the exercise time and intensity, correcting bad habits of sports, develop flexible control ability and the consciousness of taking part in physical exercise, to lay a solid foundation for lifelong physical education. 
(4) To establish the management mechanism of social participation in sports. Many universitys and universities have insufficient funds for physical education, inadequate sports facilities, and weak sports teachers, which cannot meet the practical needs of lifelong physical education development. University sports can use social force to raise funds, improve the facilities of gymnasiums and facilities, and solve some problems of sports development. University sports venues to meet the school teachers and students on the basis of daily physical activity, also need to be open to the public, in order to promote the national fitness cause, improve the physical quality and health level to make positive contribution. It can also solve the problem of insufficient maintenance funds through paid opening.

(5) We will carry out a variety of extracurricular sports activities. Extracurricular physical activity is the second classroom for university students to study sports. It is an extension of public physical education curriculum in universities. It provides students with a platform to pursue their own hobbies and display specialties. Carrying out rich and colorful extracurricular sports activities, not only can enrich the amateur cultural life of university students, build good campus sports culture atmosphere, more help to cultivate the students' interest in sports and ability, for students to the movement of the solid foundation for lifelong physical education activities, the formation of the university students' consciousness of lifelong physical education and physical exercise habits have good role in promoting.

\section{Conclusion}

The core of lifelong physical education thinking is to emphasize sports education through the life of people, and to train people to form healthy exercise habits as the ultimate goal. Therefore, the physical education reform of university in the perspective of lifelong physical education is a change that meets the requirements of The Times. The idea of lifelong physical education can effectively regulate the emotion of university students and adapt to the healthy growth of university students. In the course of sports, the accomplishment and satisfaction of cultivating university students to participate in sports activities. Lifelong physical education can improve students' ability of physical exercise, to the lifelong physical education concept throughout the whole teaching of sports, training university students' sports regulation ability, cultivate independent exercise habits, the sports self-realization in practice, physical and mental health of university students and the future development of great significance.

\section{References}

[1] B. H. Mai, J. W. Zhu, "Research on the innovation of physical education in Colleges and Universities Based on the perspective of lifelong education," Contemporary Sports Technology, vol. 7, no. 18, pp. 3-4, 2017.

[2] S. B. Nie, "The Thought about the Development between Lifelong Physical Education and School Physical Education," Yinshan Academic Journal (Natural Science Edition), vol. 31, no. 3, pp. 46-48, 2017.

[3] L. Zhang, "On the thought of lifelong physical education and the reform of physical education in colleges and universities," Science \& Technology Information, vol. 14, no. 34, pp. 151-152, 2016.

[4] K. Li, J. Yuan, "Construction of physical education system in primary and secondary schools from the perspective of Lifelong Physical Education," Contemporary Sports Technology, vol. 7, no. 18, pp. 5-6, 2017.

[5] S. B. Nie, "Study on the penetration of lifelong physical education in school physical education," Journal of Jiangsu Second Normal University (Natural Science), vol. 33, no. 6, pp. 83-85, 2017. 